\title{
PENGARUH SEKTOR INDUSTRI TERHADAP PERTUMBUHAN EKONOMI PROVINSI SULA WESI BARAT
}

\author{
The Influence Of The Industrial Sector \\ On Economic Growth Of West Sulawesi Province
}

\author{
Zulkifli \\ Email : zulkifli@iain-bone.ac.id \\ Program Studi Perbankan Syariah \\ Fakultas Ekonomi dan Bisnis Islam IAIN Bone
}

\begin{abstract}
ABSTRAK
Tujuan Penelitian ini yaitu untuk mengetahui Pengaruh Sektor Industri Terhadap Pertumbuhan Ekonomi Provinsi Sulawesi Barat. Teknik analisis data yang digunakan yaitu regresi linear sederhana. Hasil penelitian menunjukkan Sektor Industri berpengaruh positif dan signifikan Terhadap Pertumbuhan Ekonomi Provinsi Sulawesi Barat.
\end{abstract}

Kata kunci : sektor industri, pertumbuhan ekonomi

\begin{abstract}
The purpose of this study was to determine the effect of the industrial sector on economic growth in West Sulawesi province. The data analysis technique used is simple linear regression. The results showed that the Industrial Sector had a positive and significant effect on Economic Growth in West Sulawesi Province.
\end{abstract}

Key words: industrial sector, economic growth

\section{PENDAHULUAN}

Pembangunan merupakan suatu usaha untuk menciptakan kesejahteraan rakyat, dan pembangunan mencerminkan suatu proses perbaikan dari suatu masyarakat atau sistem sosial secara keseluruhan untuk bergerak maju menuju suatu kondisi yang lebih baik. Umumnya pembangunan negara-negara sedang berkembang dipusatkan pada pembangunan ekonomi melalui usaha pertumbuhan ekonomi. Proses pembangunan mengharapkan adanya pertumbuhan ekonomi yang diikuti dengan perubahan struktur ekonomi dan perubahan kelembagaan, namun proses pembangunan tidak mudah karena diperlukan waktu yang panjang.

Pembangunan Ekonomi diartikan sebagai suatu proses yang menyebabkan pendapatan per kapita penduduk suatu masyarakat meningkat dalam jangka waktu panjang. Definisi ini mengandung tiga unsur, (1) pembangunan ekonomi sebagai suatu proses perubahan yang terus menerus yang ada di dalamnya telah mengandung unsur-unsur kekuatan sendiri unsur investasi baru; (2) usaha 
meningkatkan pendapatan per kapita; (3) kenaikan pendapatan per kapita harus berlangsung dalam jangka panjang

Setiap wilayah mempunyai kewenangan dan tanggung jawab dalam memenuhi kepentingan masyarakat berdasarkan prinsip-prinsip keterbukaan, partisipasi masyarakat dan pertanggungjawaban kepada masyarakat. Sasaran pembangunan nasional secara efisien dan efektif harus dilakukan dengan perencanaan koordinasi dan keterpaduan antar sektor pembangunan yang disesuaikan dengan kondisi dan potensi yang dimiliki oleh masing-masing daerah. Umumnya tujuan pembangunan dalam kebijakan daerah adalah mengurangi disparitas atau ketimpangan pembangunan antar daerah maupun antar masyarakat, memberdayakan masyarakat, mengentaskan kemiskinan, menciptakan lapangan kerja, meningkatkan pendapatan dan kesejahteraan daerah, menjaga sumber daya alam agar bermanfaat, serta agar tercapainya kemandirian daerah.

Pertumbuhan ekonomi dari tahun ke tahun merupakan salah satu indikator dari keberhasilan pembangunan daerah, ini dapat ditunjukkan oleh nilai PDRB. PDRB dikategorikan dalam berbagai sektor perekonomian, dan pertumbuhan PDRB tidak lepas dari peran setiap sektor-sektor ekonomi tersebut, besar kecilnya kontribusi pendapatan setiap sektor perekonomian merupakan hasil perencanaan secara sektoral yang dilaksanakan oleh daerah.

Provinsi Sulawesi Barat merupakan salah satu Provinsi yang ada di Indonesia Timur. PDRB Sulawesi Barat tahun 2016 sampai 2019 terlihat mengalami peningkatan tahun 2016 PDRB Sulawesi Barat sebesar Rp. 29.282.487,06 meningkat menjadi 29.282.487,06 pada tahun 2019.

Sektor indusri yang diharapkan berkontribusi besar terhadap perekonomian Provinsi Sulawesi Barat pada tahun 2016 sampai 2019 juga mengalami peningkatan, PDRB sektor industri tahun 2016 Rp. 2.893.312,33 meningkat menjadi Rp. 3.527.509,76 pada tahun 2019.

Tabel 1 PDRB Propinsi Sulawesi Barat tahun 2016-2019

\begin{tabular}{ccc}
\hline Tahun & PDRB Sektor ndustri & PDRB \\
\hline 2016 & $2.893 .312,33$ & $29.282 .487,06$ \\
2017 & $3.123 .664,41$ & $31.111 .346,93$ \\
2018 & $3.357 .617,13$ & $32.873 .531,52$ \\
2019 & $3.527 .509,76$ & $29.282 .487,06$ \\
\hline
\end{tabular}

Sumber : BPS Kabupaten Propinsi Sulawesi Barat

Sektor Industri industri pengolahan berperan penting dalam upaya menggenjot nilai investasi dan ekspor sehingga menjadi sektor yang penting diperhatikan untuk mengakselerasi pertumbuhan ekonomi. Sektor industri dianggap sebagai the leading sektor yang mampu mendorong 
berkembangnya sektor-sektor yang lain, seperti sektor jasa dan pertanian (Arsyad, 2010). Struktur perekonomian suatu wilayah yang relatif maju ditandai oleh semakin besarnya peran sektor industri pengolahan dalam menopang perekonomian wilayah tersebut. Sektor ini telah menggantikan peran sektor tradisional (pertanian) dalam penyerapan tenaga kerja dan sumber pendapatan wilayah

Berdasarkan data Badan Pusat Statistik (BPS) Sulawesi Barat menunjukkan, ada tiga sektor yang berkontribusi besar terhadap pertumbuhan ekonomi Di Provinsi Sulawesi Barat pada tahun 2018. Ketiga sektor itu adalah Sektor Pertanian dengan kontribusi sebesar 42\%, kemudian sektor industri sebesar $10 \%$ dan sektor perdagangan juga dengan kontribusi $10 \%$

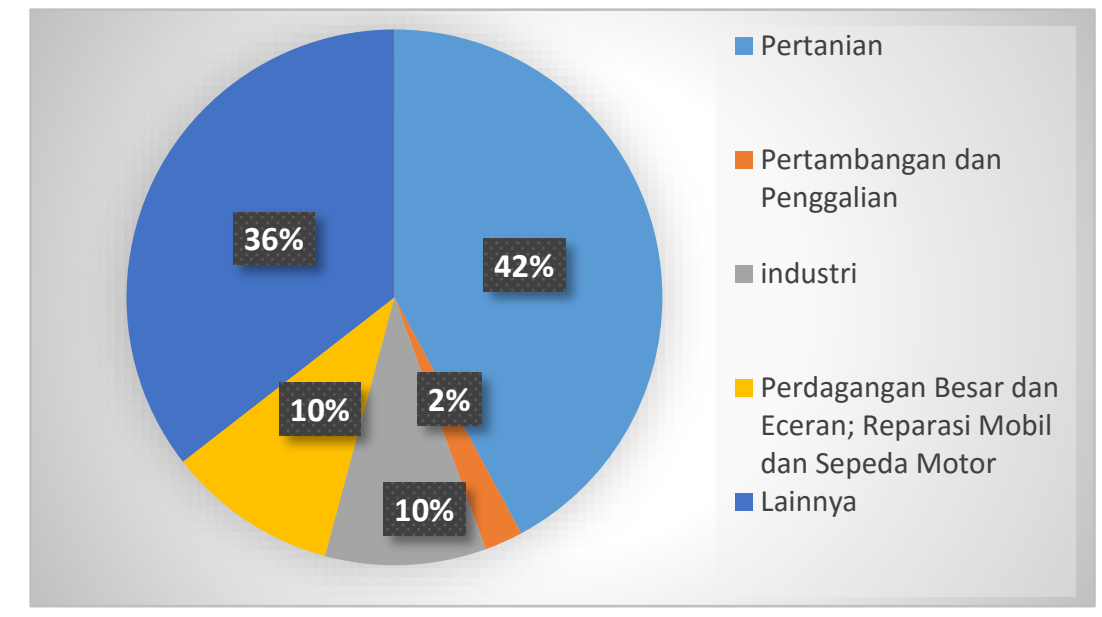

Gambar 1. Distribusi PDRB Sulawesi Barat Berdasarkan lapangan Usaha tahn 2018

Sumber : BPS Sulawesi Barat

Berdasarkan latar belakang yang telah diuraikan diatas, maka Tujuan Penelitian ini yaitu untuk mengetahui Pengaruh Sektor Industri Terhadap Pertumbuhan Ekonomi Provinsi Sulawesi Barat

\section{METODE PENELITIAN}

\section{A. Lokasi dan Waktu Penelitian}

Penelitian ini dilaksanakan di Provinsi Sulawesi Barat, dengan menggunakan data sekunder dimana pengumpulan data ini diperoleh dari Badan Pusat Statistik Provinsi Sulawesi Barat. Penelitian ini dimulai sejak bulan Februari - April 2020.

B. Jenis dan Sumber Data

Jenis dan Sumber Data yang digunakan dalam penelitian ini merupakan data sekunder, yaitu PDRB Provinsi Sulawesi Barat periode 2010-2019, data ini digunakan untuk analisis pertumbuhan sektor industri pengolahan. Data ini diperoleh dari Badan Pusat Statistik (BPS) Provinsi Sulawesi Barat.

C. Teknik Analisis data 
Dalam penelitian ini untuk mengetahui Pengaruh sektor industri terhadap pertumbuhan ekonomi Di Provinsi Sulawesi Barat dilakukan uji regresi linear sederhana.

Model yang digunakan dalam penelitian ini adalah :

$$
\mathrm{Y}=\alpha+\beta \mathrm{X}+\mathrm{e}
$$

Keterangan :

$$
\begin{array}{ll}
\mathrm{Y} & : \text { Pertumbuhan ekonomi } \\
\mathrm{X} & : \text { Sektor industri } \\
\alpha & : \text { Konstanta } \\
\beta & : \text { Nilai Koefisien X1 dan X2 } \\
\mathrm{e} & \text { : Error Term }
\end{array}
$$

\section{HASIL PENELITIAN DAN PEMBAHASAN}

\section{A. Hasil Penelitian}

\section{PDRB Sektor Industri Propinsi Sulawesi Barat}

Sektor Industri Propinsi Sulawesi Barat tahun 2010 -2019 juga terus mengalami peningkatan, hal ini ditunjukkan dengan angka PDRB sektor industri atas dasar harga konstan yang tercipta terus meningkat tahun 2010 PDRB sektor industri Propinsi Sulawesi Barat sebesar Rp. 1.497.039,80 (juta) dan tahun 2019 PDRB sektor industri meningkat menjadi Rp. 3.527.509,76 (juta). Meskipun peningkatannya menunjukkan tren positif, namun pada tahun tertentu PDRB sektor industri terjadi penurunan yaitu tahun 2015 dari Rp. 2.966.345,93(juta) menjadi Rp. 2.893.312,33 (juta), pada tahun 2016.

Tabel 2 PDRB sektor Industri Propinsi Sulawesi Barat Tahun 2010-2019

\begin{tabular}{lc}
\hline Tahun & PDRB Sektor ndustri \\
\hline 2010 & $1.497 .039,80$ \\
2011 & $1.720 .113,55$ \\
2012 & $1.836 .869,57$ \\
2013 & $1.967 .038,33$ \\
2014 & $2.668 .880,41$ \\
2015 & $2.966 .345,93$ \\
2016 & $2.893 .312,33$ \\
2017 & $3.123 .664,41$ \\
2018 & $3.357 .617,13$ \\
2019 & $3.527 .509,76$ \\
\hline
\end{tabular}


Sumber : BPS Propinsi Sulawesi Barat

\section{PDRB Propinsi Sulawesi Barat}

Berdasarkan data pada tabel 1.2 dibawah dapat dilihat bahwa pertumbuhan ekonomi Propinsi Sulawesi Barat tahun 2010-2019 mengalami peningkatan yang ditunjukkan oleh nilai PDRB yang meningkat setiap tahunnya yaitu pada tahun 2010 jumlah PDRB Propinsi Sulawesi Barat sebanyak 17.183.831,83 (ribu Juta) meningkat menjadi Rp. 32.873.531,52 (ribu juta) jiwa di tahun 2019

Tabel 3 PDRB Proponsi Sulawesi Barat tahun 2010-2019

\begin{tabular}{lc}
\hline Tahun & PDRB \\
\hline 2010 & $17.183 .831,83$ \\
2011 & $20.786 .885,76$ \\
2012 & $22.227 .392,55$ \\
2013 & $24.195 .655,00$ \\
2014 & $25.964 .432,14$ \\
2015 & $27.524 .767,06$ \\
2016 & $29.282 .487,06$ \\
2017 & $31.111 .346,93$ \\
2018 & $32.873 .531,52$ \\
\hline 2019 &
\end{tabular}

Sumber : BPS Propinsi Sulawesi Barat

B. Pembahasan

Berdasarkan hasil olah data diperoleh persamaan untuk regresi linear sederhana sebagai berikut :

$$
Y=7203249,69+6,970 X+e
$$

Dari persamaan regresi linear sederhana diperoleh nilai konstanta sebesar 7203249,69. Artinya bahwa jika Produk domestik bruto (PDRB) sektor industri Propinsi Sulawesi Barat bernilai 0, maka besarnya Produk domestik bruto (PDRB) Propinsi Sulawesi Barat adalah sebesar 7203249,69. Selanjutnya nilai koefisien regresi variabel sektor industri sebesar 6,970 menunjukkan bahwa jika nilai PDRB sektor Industri naik sebesar 1 maka nilai PDRB Propinsi Sulawesi Barat akan naik sebesar 6,970 . 
Kemudian apabila dilihat dari tanda koefisien regresi bernilai positif $(6,970)$ menunjukkan PDRB sektor Industri berpengaruh positif terhadap Produk domestik bruto (PDRB) Propinsi Sulawesi Barat, hal ini mengandung arti bahwa untuk setiap peningkatan variabel PDRB sektor Industri maka akan menyebabkan peningkatan Produk domestik bruto (PDRB) Propinsi Sulawesi Barat. Dan nilai signifikansi sebesar 0,000 lebih kecil dari $0,05(0,000<0,05)$ menunjukkan bahwa PDRB sektor Industri berpengaruh signifikan terhadap Produk domestik bruto (PDRB) Propinsi Sulawesi Barat

Tantangan yang dihadapi Propinsi Sulawesi Barat dalam pelaksanaan strategi pembangunannya sebagaimana hasil penelitian tersebut di atas adalah bagaimana lebih meningkatkan produktivitas dan efisiensi semua sub sektor industri pengolahan dalam menghasilkan berbagai komoditi agar dapat memberikan nilai tambah yang sebesar-besarnya kepada masyarakat, dengan mengoptimalkan segala potensi yang dimiliki daerahnya. Peningkatan produktivitas dan efisiensi semua sub sektor industri pengolahan di Propinsi Sulawesi Barat dapat dilakukan apabila pemerintah mengetahui potensi daerahnya.

Dengan demikian perlu adanya upaya dalam memajukan sektor industri pengolahan, mengingat besarnya peran sektor tersebut baik dalam perekonomian. Upaya yang perlu dilakukan adalah dengan mengidetifikasi peran masing-masing sub sektor industri pengolahan untuk memajukan sektor industri pengolahan. Sektor industi pengolahan Propinsi Sulawesi Barat tentunya memiliki sub sektor yang masing-masing memberikan kontribusi terhadap PDRB. Industri pengolahan Propinsi Sulawesi Barat memiliki 16 sub sektor yang pastinya berbeda-beda kontribusinya terhadap PDRB Propinsi Sulawesi Barat.

Hasil penelitian ini sejalan dengan penelitian yang dilakukan Ahmad Shodiqin (2018) yang menunjukkan bahwa sektor industri pengolahan berpengaruh terhadap pertumbuhan ekonomi Kota Bandar Lampung. Sektor industri dianggap sebagai sektor pemimpin (the leading sektor), Sesuai dengan teori Hirschman, pertumbuhan yang cepat dari satu atau beberapa industri mendorong perluasan industri-industri lainnya yang terkait dengan sektor industri yang tumbuh lebih dulu. Pertumbuhan ekonomi berkaitan dengan proses peningkatan produksi barang dan jasa di dalam kegiatan ekonomi masyarakat dan diukur dengan meningkatnya hasil produksi dan pendapatan. Produk Domestik Regional Bruto (PDRB) dapat dijadikan sebagai salah satu indikator guna melihat keberhasilan pembangunan perekonomian disuatu wilayah. PDRB dapat menggambarkan kemampuan suatu daerah mengelola sumberdaya alam yang dimilikinya. Oleh karena itu, besaran PDRB yang dihasilkan oleh masing masing daerah sangat bergantung kepada potensi faktor-faktor produksi di daerah tersebut. 


\section{KESIMPULAN DAN SARAN}

Berdasarkan hasil penelitian dan pembahasan hasil penelitian dapat disimpulkan bahwa sektor industri berpengaruh positif dan signifikan Terhadap pertumbuhan ekonomi Provinsi sulawesi barat. Adapun saran dari penelitian ini yaitu :

1. Pemerintah Kabupaten Majene mengembangkan sektor industri karena dapat menumbuhkan pertumbuhan ekonomi secara nyata di Kabupaten Majene

2. Untuk peneliti selanjutnya dengan tema yang sama dapat melakukan penelitian lanjutan dampak dari pertumbuhan ekonomi terhadap kemiskinan di Kabupaten Majene.

\section{DAFTAR PUSTAKA}

Arikunto, S. 2010. Prosedur Penelitian Suatu pendekatan Praktek. Jakarta: Rineka Cipta. Arsyad, L. 2016. Ekonomi Pembangunan. Edisi Kelima. STIE YKPN. Yogyakarta.

Astuti, R. R. 2015. Analisis Pengaruh Jumlah Penduduk, Pertumbuhan Ekonomi, Pendidikan Dan Kesehatan Terhadap Jumlah Penduduk Miskin Di Indonesia Tahun 2004 - 2012. Yogyakarta : FE UNY.

Ahmad Shodiqin 2018 Pengaruh Sektor Industri Pengolahan Terhadap Pertumbuhan Ekonomi Kota Bandar Lampung Periode 2010-2016 Perspektif Ekonomi Islam. Skripsi Fakultas Ekonomi Dan Bisnis Islam Universitas Islam Negeri Raden Intan Lampung

Arifatul Chusna 2013 Pengaruh Laju Pertumbuhan Sektor Industri, Investasi, Dan Upah Terhadap Penyerapan Tenaga Kerja Sektor Industri Di Provinsi Jawa Tengah Tahun 1980-2011 Skripsi Jurusan Ekonomi Pembangunan Fakultas Ekonomi Universitas Negeri Semarang

Ayu azhari amin 2015 Peranan Sektor Industri Pengolahan Terhadap Perekonomian Dan Penyerapan Tenaga Kerja Di Provinsi Sulawesi Utara. Skripsi Universitas Samratulangi Fakultas Pertanian Jurusan Sosial Ekonomi Manado

Ghozali, I. \& Dwi R. 2013. Analisis Multivariat Dan Ekonometrika : Teori, Konsep, dan Aplikasi dengn Eviews 8. Semarang :Universitas Diponegoro Semarang. Gujarati,

N. D. \& Dawn, C.P. 2013. Dasar-dasar Ekonometrika Buku 2. Jakarta: Salemba Empat.

Hadi, S. 2004. Jhingan, M.L. (2000). Ekonomi Pembangunan dan Perencanaan. Penerjemah: D. Guritno. Jakarta: PT Raja Grafindo Persada.

Kuncoro, M. 2006. Ekonomi Pembangunan, Teori, Masalah dan Kebijakan. UPP AMP YKPN: Yogyakarta.

Kuncoro, M. 2010. Masalah, Kebijakan, dan Politik: Ekonomika Pembangunan. Yogyakarta: UPP STIM YKPN.

Kuncoro, M. 2003. Metode Riset Untuk Bisnis dan Ekonomi. Jakarta : Erlangga.

Nasir, M. M. Saichudin \& Maulizar 2008. Analisis Faktor-Faktor yang Mempengaruhi Kemiskinan Rumah Tangga di Kabupaten Purworejo. Jurnal Eksekutif. Vol. 5 No. 4, Agustus 2008. Lipi: Jakarta. 108

Niswati, K. 2014. Faktor-Faktor Yang Mempengaruhi Kemiskinan Di Daerah Istimewa Yogyakarta Tahun 2003-2011. Ekonomi regional Vol. 9, No.2, September 2014. Universitas Jenderal Soedirman.

Simatupang, P. \& Saktyanu K. D. 2003. Produksi Domestik Bruto, Harga, dan Kemiskinan, Media Ekonomi dan Keuangan Indonesia. Hal. 191 - 324, Vol. 51, No 3. 
Permana, A.Y. 2012. Analisis Pengaruh PDRB, Pengangguran, Pendidikan, Dan Kesehatan Terhadap Kemiskinan Di Jawa Tengah Tahun 2004-2009. Semarang: Fakultas Ekonomika Dan Bisnis, Universitas Diponegoro.

Prasetyo, A. A. 2010. Analisis Faktor-Faktor Yang Mempengaruhi Tingkat Kemiskinan Di Jawa Tengah (Studi Kasus 35 Kabupaten/Kota Di Jawa Tengah Tahun 2003-2007. Semarang: FE Universitas Diponegoro.

Suryandar, A.N. 2017 Pengaruh Pertumbuhan Ekonomi, Pendidikan, Dan Kesehatan Terhadap Tingkat Kemiskinan Di Provinsi Daerah Istimewa Yogyakarta Tahun 2004-2014. Skripsi Program Studi Pendidikan Ekonomi Fakultas Ekonomi Universitas Negeri Yogyakarta 